\title{
O MARCADOR DE GÊNERO FEMININO -ABA DO WAPIXANA (ARUÁK)
}

\author{
THE FEMALE GENDER MARK -ABA WAPIXANA (ARUÁK)
}

\author{
Manoel Gomes dos SANTOS 1 \\ Zoraide dos ANJOS²
}

Resumo: Culturas distintas fazem diferentes escolhas e representações léxico-gramaticais da realidade. Em termos da categoria de gênero, enquanto o português emprega, regularmente, apenas um paradigma envolvendo o morfema $-a$, de feminino, oposto à ausência de marca ou a um morfema de masculino, o wapixana apresenta dois paradigmas: um para nomes inalienáveis (termos de parentesco), que opõe o morfema - ru de feminino ao morfema - $r \dot{i}$, de masculino, e outro para nomes alienáveis, que opõe o morfema- $a b a$, de feminino, à ausência de marca para masculino. $\mathrm{O}$ morfema -aba deste último paradigma restringe-se a nomes cujos referentes exibem o traço [tanimado], exceto nomes de parentescos, que obedecem ao primeiro paradigma. Embora atestados empiricamente tais paradigmas, persiste a questão do status do formativo - $a b a$, tratado por Santos (2006) como termo de classe e, consequentemente, como formador de palavra e não como marcador flexional de gênero. Neste trabalho, então, investigamos, numa perspectiva tipológicofuncional, especialmente nos termos de Dixon (1986) e Grinevald (2000), a natureza desse marcador: se lexical ou flexional. Os resultados apontam para uma revisão da posição de Santos.

Palavras-chave: Wapixana. Classificação Nominal. Gênero. Marcador de Gênero - $a b a$.
Abstract: Different cultures make different choices and lexical-grammatical representations of reality. In terms of the gender category, while Portuguese regularly employs one paradigm involving feminine morpheme $-a$, as opposed to the unmarked or the masculine morpheme, Wapixana presents two paradigms: one for inalienable names (kinship terms), which opposes the morpheme -ru feminine to the morpheme - $r \dot{i}$, masculine, and another to alienable names, which opposes the morpheme $-a b a$, feminine, to the absence of brand for the masculine. The morpheme - $a b a$ of the latter paradigm is restricted to names whose referents display the feature [+ animate], except kinship names, which obey the first paradigm. Although empirically attested in such paradigms, the issue of the status of the formative $-a b a$ persists, treated by Santos (2006) as a class term and, consequently, as a word and not as a flexional marker of gender. In this paper, we investigate, from a typologicalfunctional perspective, especially in terms of Dixon (1986) and Grinevald (2000), the nature of this marker: whether lexical or flexional. The results point to a review of Santos's position.

Keywords: Wapixana. Nominal classification. Gender. Female gender mark - aba.

1 Universidade Federal de Roraima (UFRR), Boa Vista, Roraima, Brasil; melgsantos@uol.com.br; https://orcid.org/0000-0002-8025-5577

2 Universidade Federal de Roraima (UFRR), Boa Vista, Roraima, Brasil; zoraide.anjos@gmail.com; https://orcid.org/0000-0001-9682-8408 


\section{Introdução}

Este trabalho tem como propósito investigar, à luz do modelo tipológico-funcional, a natureza do morfe-aba do morfema \{feminino\} de nomes não obrigatoriamente possuídos ou alienáveis na língua wapixana. Esse marcador de gênero, embora reconhecido por Santos (2006), é por ele tratado como termo de classe, instigando, assim, reflexões sobre o real status desse formativo, quer dizer, se tal marcador, enquanto designador de gênero, tem natureza gramatical, ou, se, enquanto termo de classe, tem natureza lexical, isto é, compõe o sistema de formação de palavras da língua wapixana.

Reflexões sobre a natureza dessas duas categorias linguísticas, gênero (classes de nomes) e termos de classe, são aqui tratadas, especialmente, com base em Dixon (1986) e Grinevald (2000), o que permite observar, de forma mais pormenorizada, as características de cada uma dessas categorias, ou seja, a posição que cada uma ocupa na tipologia dos sistemas de classificação nominal e as peculiaridades privativas de cada uma delas, o que propicia reconhecer a qual delas pertence o morfema - $a b a$ da língua wapixana.

Os assuntos aqui tratados obedecem à seguinte ordem de exposição. Na seção seguinte, fazemos uma breve apresentação da perspectiva teórica assumida, considerando, especialmente, aspectos relacionados ao tema em apreço; em seguida, passamos em revista a posição de Santos (2006) acerca da expressão de gênero em wapixana; depois, procedemos à análise propriamente dita do status do marcador de feminino -aba dessa língua; finalmente, tecemos nossas considerações finais acerca dos resultados alcançados.

\section{Perspectiva teórica}

Uma vez que este estudo envolve a explicitação de semelhanças e diferenças entre uma categoria gramatical, o gênero (classes de nomes), e uma categoria lexical, os termos de classe, a abordagem tipológico-funcional aqui empregada apoia-se, especialmente, em Grinevald (2000), com o intuito de situar ambas essas categorias num sistema mais amplo de classificação nominal, e em Dixon (1986), com o intento de estabelecer o cotejo entre características peculiares de cada uma dessas categorias e, assim, definir com mais precisão o status do marcador de feminino -aba do Wapixana.

Observando os desafios enfrentados pela tradição no que diz respeito à falta de uma sistematização tipológica precisa referente à classificação nominal, Grinevald (2000) propõe uma tipologia de caráter morfossintático com vistas a uma ordenação adequada dos sistemas de classificação nominal. Assim, assumindo uma perspectiva funcionaltipológica e considerando a sobreposição semântica e morfossintática existente entre 
os vários sistemas de classificação nominal (termos de medida, termos de classe, classificadores e gênero ou classes de nomes), propõe que os sistemas de classificação nominal ficam mais bem descritos se situados em um contínuo ao longo de um eixo que vá de uma extremidade lexical a uma extremidade gramatical, como se pode observar na figura apresentada pela autora (ibid., p. 61), em que os sistemas termos de classe e gênero (classes de nomes) concernentes aos propósitos deste trabalho encontram-se em negrito:

Figura 1. Sistemas de classificação nominal

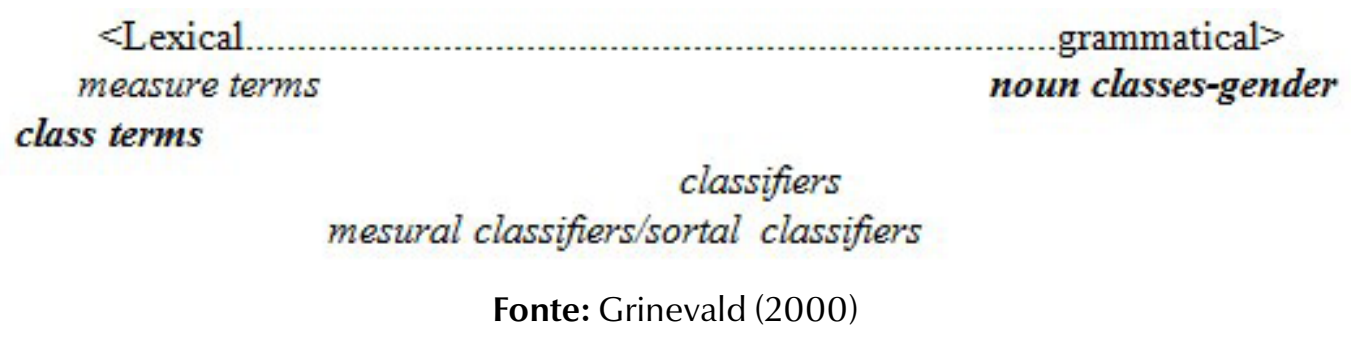

Como se observa nessa figura, as duas categorias relevantes para este trabalho, termos de classe e gênero (ou classes de nomes), situam-se no contínuo do eixo dos sistemas de classificação nominal em posições simetricamente opostas, quer dizer, termos de classe ocupam uma posição no extremo lexical, enquanto gênero (ou classes de nomes) posiciona-se no extremo gramatical.

Com efeito, as localizações dessas duas categorias no contínuo do eixo dos sistemas de classificação nominal são fundamentadas nas definições de tais categorias apresentadas na literatura sobre os sistemas de classificação nominal. Assim, conforme Grinevald (2000, p. 59, tradução nossa $\left.{ }^{3}\right)$ :

Os termos de classe são morfemas classificadores que participam da gênese do léxico de uma língua. [...] A diferença entre morfemas derivacionais e termos de classe que são usados no processo de composição nem sempre é resolvida [...]. Os termos de classe são morfemas classificadores de origem lexical clara e mostram graus variados de produtividade no léxico de uma língua.

Portanto, termos de classe constituem morfemas de origem nitidamente lexical que atuam na formação do léxico de uma língua, semelhantemente ao que ocorre com os processos de derivação e de composição tradicionalmente conhecidos. Como

3 No original: "Class terms are classifying morphemes which participate in the lexico-genesis of a language. [...] The difference between derivational morphemes and class terms that are used in compounding process is not always worked out [...]. Class terms are classifying morphemes of clear lexical origin and show varying degrees of productivity in the lexicon of a language". 
se percebe, essa categoria é de natureza lexical não só pelo fato de seus morfemas funcionarem na construção do léxico de uma língua senão também por esses próprios morfemas originarem-se transparentemente do léxico. Segundo Grinevald (idem), um dos domínios semânticos mais comuns da expressão dessa categoria é aquele relacionado ao mundo das plantas, o qual é ilustrado com os exemplos de (01) do wapixana, a seguir ${ }^{45}$ :
a. ak-a-i
'fruta'
fruta-EP-NPOSS
b. atamin-ak
árvore-TCL:fruta
'fruta da árvore'
c. wabu-ak
açaí-TCL:fruta
'fruta do açaizeiro'
d. at Jawii-ak
alho-do-mato-TCL:fruta
'fruta do alho-do-mato'

Em (01), os exemplos de (01b-d) apresentam o termo de classe - $a$ k 'fruta' recorrentemente empregado com termos que designam plantas, respectivamente, com atamin 'árvore', em (01b), com wabu 'açaizeiro', em (01c), e com atfawii 'alho-do-mato', em (01d), formando, respectivamente, os compostos atamin-ak 'fruta da árvore', wabu-ak 'fruta do açaizeiro' e atfawii-ak 'fruta do alho-do-mato'. Observa-se nesses exemplos do wapixana uma característica geral dos termos de classe mencionada por Delancey (1986) em seu estudo sobre as línguas Tai, a saber, em todos os compostos formados, o termo de classe constitui o núcleo, isto é, contém o sentido geral que é especificado pela outra parte do composto, que o antecede. O exemplo de (01a), por sua vez, evidencia o fato de que o termo de classe $a k$ 'fruta' do wapixana tem origem lexical, quer dizer, provém do radical da palavra $a k a i$ 'fruta', condição necessária, conforme a definição apresentada acima, para que um morfema opere como um termo de classe.

Embora, similarmente a um nome como tree do inglês, em construções como apple tree 'macieira', banana tree 'bananeira', ocorra recorrentemente na produção de compostos, o termo de classe difere desse tipo de nome por constituir sempre forma presa. Em (01), apenas a forma em (01a) akai 'fruta' (com sufixo -i de não possuído, já que um nome inalienável) é forma livre; em (01b-d), a forma - $a k$ (desprovida desse sufixo), correspondente ao termo de classe, é sempre presa. Em Wapixana, o surgimento dos

\footnotetext{
4 Todos os exemplos apresentados neste trabalho são fornecidos em transcrição fonêmica.

5 As seguintes abreviaturas são usadas neste trabalho: DIST distal; EP epêntese; $\mathrm{F}$ feminino; $\mathrm{M}$ masculino; $\mathrm{MI}$ modo indicativo; NPOSS não possuído; O objeto; PROX próximo; $\mathrm{S}$ sujeito; TCL termo de classe; 2 segunda pessoa do singular.
} 
termos de classe parece estreitamente relacionado à categoria de posse, de modo que uma forma lexical em construções sintáticas genitivas pode assumir uma função classificatória (categoria de classificadores) que, com o uso ao longo do tempo, pode desenvolver, no nível morfológico, o termo de classe.

Em relação à categoria de gênero (ou classes de nomes), por outro lado, Dixon (1986, p. 105, tradução nossa ${ }^{6}$ ) assim se reporta:

As classes de nome (ou gênero) constituem um sistema gramatical obrigatório, onde cada substantivo escolhe uma dentre um pequeno número de possibilidades. As formas de marcar a classe de nome incluem um prefixo para o substantivo (e geralmente também para outros constituintes do sintagma nominal ou da frase que mostram concordância com ele), como nas línguas banto; um artigo obrigatório, como em francês e alemão; ou um sufixo flexional que mostra um portmanteau de caso e gênero, como no latim.

Como se observa nesse excerto, gênero (ou classes de nomes) constitui uma categoria obrigatoriamente gramatical, o que é explicitado pelo pequeno número de subcategorias de gênero a que pode pertencer um nome; pela maneira como essa categoria é marcada, quer dizer, o morfema marcador de gênero pode estar presente não apenas no próprio nome, mas em outros constituintes que com ele estabeleçam relações de concordância; e, finalmente, pela possibilidade de o morfema marcador de gênero também marcar a categoria de caso cumulativamente.

Ainda, conforme esse autor, enquanto necessariamente gramatical, a categoria classes de nomes ou gênero constitui sistema fechado que abrange todos os nomes da língua (que reúnam os requisitos para sua aplicação), cujo número de subcategorias, sendo limitado, normalmente vai de um mínimo de duas a um máximo de vinte possibilidades, havendo línguas em que cada nome pertence a exatamente uma subcategoria. Exemplos desse sistema de classificação de nomes em wapixana serão oferecidos na seção seguinte, na qual é abordada a expressão de gênero nessa língua.

Em resumo, o confronto entre essas duas categorias permite observar suas propriedades peculiares. Assim, enquanto a categoria "termos de classe" está estreitamente

6 No original: "Noun classes constitute an obligatory grammatical system, where each noun chooses one from a small number of possibilities. Ways of marking noun class include a prefix to the noun (and usually also to other constituents in the noun phrase, or in the sentence, that show concord with it), as in Bantu languages; an obligatory article, as in French and German; or an inflectional suffix that shows a portmanteau of case and noun class, as in Latin.". 
relacionada ao léxico - isto é, tem origem transparentemente lexical e opera na formação do léxico da língua, de forma que se aplica a um pequeno grupo de nomes, não sendo, pois, nem geral, nem sistemática - a categoria de gênero ou classes de nomes vincula-se ao sistema gramatical e, assim, aplica-se à totalidade dos nomes que a requerem, opera em processo de concordância e pode atuar em conjunto com outras categorias gramaticais, tais como a categoria de caso.

\section{A expressão de gênero em wapixana}

Antes de tratar propriamente do status do marcador de feminino - $a b a$ em wapixana, o que será feito na próxima seção, necessário se faz verificar como se estabelece a categoria de gênero nessa língua. A literatura tipológico-funcional pertinente mostra que culturas distintas fazem diferentes escolhas e representações léxico-gramaticais da realidade (SAPIR, 1969; ENFIELD, 2004) e que a categorização linguística é o que há de mais básico no pensamento humano (LAKOFF, 1987). Nesse sentido, diferentemente do português, que exibe apenas um paradigma para a marcação da categoria de gênero, no qual, regularmente, tem-se um morfe - $a$ do morfema \{feminino\} oposto à ausência de marcas ou a um morfe marcador do masculino, o wapixana exibe um sistema mais complexo de dois paradigmas relacionados à distinção que faz essa língua, como ocorre com as línguas Aruák em geral (PAYNE, 1991; AIKHENVALD, 1999), quanto à categoria de posse; distinção essa que divide os nomes em duas subcategorias, a saber, nomes obrigatoriamente possuídos (ou inalienáveis), que fazem referência a partes do corpo, partes de plantas, relações de parentesco e a alguns objetos culturais, e nomes não obrigatoriamente possuídos (ou alienáveis), cujos domínios semânticos referidos ainda não se encontram identificados. Tais subcategorias são codificadas em marcadores léxicogramaticais, como se pode observar nos exemplos que seguem:
a. zinadi-i
'prima'
prima-NPOSS
b. pi-zinadi
'tua prima'
2-prima

(03)
a. zakap
'roça'
roça
b. pi-zakap-a-n
2-roça-EP-POSS
'tua roça' 
Os exemplos em (02) ilustram a subcategoria de nomes obrigatoriamente possuídos (ou inalienáveis), enquanto os exemplos em (03) ilustram a subcategoria de nomes não obrigatoriamente possuídos (ou alienáveis). Como se pode observar, o nome obrigatoriamente possuído (no exemplo, zinaqii 'prima') caracteriza-se pela presença do sufixo -i, quando não há um possuidor explícito, como ilustrado em (02a), e pela ausência desse sufixo quando a construção exibe um possuidor explícito, como se observa em (02b), em que o prefixo $p i^{-}$- de segunda pessoa constitui o possuidor. O nome não obrigatoriamente possuído (no exemplo, zakap 'roça'), por sua vez, caracteriza-se pela ausência de qualquer marca, quando não há possuidor explícito, como em (03a), e pela presença de um sufixo marcador de posse (neste exemplo $-n$ ), quando explicitamente traz um possuidor, como em (03b), cujo possuidor é também codificado pelo sufixo $p \dot{i}$ - de segunda pessoa.

Portanto, a divisão, com base na posse, entre categorias de nomes obrigatoriamente possuídos ou inalienáveis e nomes não obrigatoriamente possuídos ou alienáveis, como observado por Santos (2006), é relevante para o tema desta seção - o gênero ou classes de nomes -, uma vez que a distinção de gênero em wapixana, calcada na distinção entre sexos $^{7}$, opõe as subcategorias de masculino e de feminino em dois paradigmas distribuídos conforme seja o nome inalienável ou alienável. Assim, a língua exibe um paradigma privativo para nomes que exijam essa distinção no âmbito dos nomes obrigatoriamente possuídos, notadamente, os termos de parentesco, e outro especificamente para os nomes que exijam tal distinção entre os nomes não obrigatoriamente possuídos, notadamente, nomes que façam referência a entidades caracterizadas pelo traço [+animado], com exceção, é claro, dos termos de parentesco.

Para os nomes obrigatoriamente possuídos ou inalienáveis, o paradigma consiste na oposição entre o morfema sufixal - $r$, que designa masculino, e o morfema sufixal - $r u$, que designa o feminino, como demonstram os exemplos que seguem:

$\begin{array}{rlr}\text { a. } & \text { da-i-a- } \ell^{i} & \text { 'esposo' } \\ & \text { gênese-NPOSS-EP-M } & \\ \text { b. } & \text { da-i-a- } r u & \text { 'esposa' } \\ & \text { gênese-NPOSS-EP-F } & \end{array}$

7 A oposição de gênero em Wapixana é marcada apenas para entidades dotadas de sexo; entidades não dotadas de sexo são marcadas como masculino (MELO, 2019). 
Em (04), os sufixos - ri e - ru marcam, respectivamente, a distinção de referência a indivíduo do sexo masculino (04a) e de referência a indivíduo do sexo feminino (04b).

De acordo com a caracterização do sistema de classes de nome ou gênero apresentado na seção anterior, em obediência ao padrão de concordância da língua, a marca de concordância se aplica além dos limites da palavra, como se pode observar nos exemplos que seguem:
a. tawi- $r$ i: daunaiur
'aquele homem'
DIST-M homem
b. tawi- $r u$ : zin

DIST-F mulher

(06) a. zinn $u_{i}$-ipai-a-n zamaka

mulher 3FS-acabar-EP-MI rede

'a mulher acabou a rede'

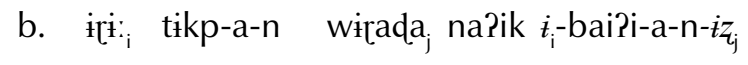

3MS ver-EP-MI jabuti e 3MS-flechar-EP-MI-3MO

'ele viu o jabuti e atirou nele'

Em (05), nos limites do sintagma, observam-se os sufixos marcadores de gênero (em itálico) nos demonstrativos. Em (06), as informações de gênero exibidas nos verbos aparecem fundidas com a categoria de caso, o que constitui mais uma especificidade do sistema de gênero vista na seção anterior, e são marcadas pelo prefixo $u$ - da forma verbal uipaian 'ela acabou', em (06a), que codifica, além do gênero feminino, a função sintática de S (sujeito) de seu correferente zin 'mulher'; e pelos afixos $i^{-}$-, que codifica gênero masculino e função sintática $S$ (sujeito) de seu correferente $i t r i$ : ' $3 \mathrm{MS}^{\prime}$, e -iż, que codifica gênero masculino e função sintática $O$ (objeto) de seu correferente witrada 'jabuti' na forma verbal ibai'ianiz 'ele atirou nele', em (06b), como sinalizado pela indexação.

No que diz respeito ao sistema de classes de nome ou gênero para nomes alienáveis, o paradigma consiste na oposição do morfema sufixal-aba, para o feminino, à ausência de marca para o masculino, como se pode observar nos exemplos a seguir:
a. $\quad \mathrm{kuji}-\varnothing$
'porco'
b. kufi-aba
'porca'

porco-TCL:F 
(08)
a. kudui- $\varnothing$
'anta-macho'
b. kudui-aba
'anta-fêmea'
anta-TCL:F

Em (07) e (08), os nomes não obrigatoriamente possuídos ou alienáveis kufi 'porco', em (07a), e kuqui 'anta-macho', em (08a), que se apresentam na subcategoria de gênero masculino, não marcado, como sinalizado pelo morfe $-\varnothing$, recebem morfema sufixal - aba para constituírem as formas correspondestes à subcategoria de gênero feminino, respectivamente, kufiaba 'porca', em (07b), e kuquiaba 'anta-fêmea', em (08b).

\section{O marcador de gênero feminino -aba em Wapixana}

Com respeito especificamente ao morfema - $a b a$, marcador da subcategoria de gênero feminino dos nomes não obrigatoriamente possuídos ou alienáveis, Santos (2006, p. 141) faz a seguinte observação:

Embora, do ponto de vista semântico, o sufixo -aba apresente para os nomes alienáveis o mesmo conteúdo que o sufixo - ru apresenta para os nomes inalienáveis, isto é, marcar como feminino o nome ao qual se agrega, ele deve ser considerado um termo de classe e não uma típica desinência de gênero.

Em defesa de sua posição, o autor apresenta os seguintes exemplos:

(09)
a. kitiki-aba
'galinha'
galo/galinha-TCL:F
b. kiriki
'galo/galinha'
galo/galinha

(10)
a. da-i-a-ru
'esposa'
gênese-NPOSS-EP-F
b. *da-i
'esposa'
gênese-NPOSS

Acerca desses exemplos, argumenta que, para nomes não obrigatoriamente possuídos ou alienáveis, como aquele em (09), tanto a construção que exibe a marca de gênero feminino-aba, kiriki-aba'galinha' em (09a), quanto a construção que não apresenta tal marca, kitikki 'galo/galinha' em (09b), são usadas regularmente; enquanto, para nomes 
obrigatoriamente possuídos ou inalienáveis, somente a construção marcada abertamente com o morfema - ru é permitida para a expressão do feminino, daí a aceitabilidade de daiaru 'esposa' (10a), mas a inaceitabilidade de *dai 'esposa' em (10b).

Seguindo essa mesma linha de raciocínio acerca de gênero de nomes alienáveis, afirma que uma palavra como a que designa "mulher, menina" em wapixana, que é inerentemente feminina, pode apresentar duas formas, uma despida do marcador de feminino e outra marcada abertamente com esse morfema, como se pode observar em (11):
a. zin-aba
'mulher, menina'
mulher/menina-TCL:F
b. zin
'mulher/menina'
mulher/menina

Em seguida, confrontando aquelas formas de (09a) kirikiaba 'galinha'/ (09b) kiriki 'galo/galinha' com estas formas de (11a) zinaba /(11b) zin 'mulher, menina', observa que, enquanto as formas marcadas pelo sufixo -aba em (09a) e (11a) correspondem sempre ao feminino, as formas em (09b) e (11b), despidas desse sufixo, diferem em emprego, de

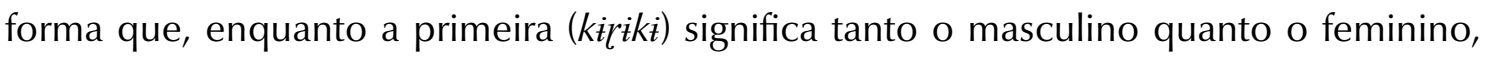
como visto acima, a segunda (zin) têm interpretação apenas de feminino.

Diante disso, Santos (2006) sugere que o marcador de gênero feminino dos nomes alienáveis - $a b a$ não deveria ser considerado um típico morfema flexional, pois seu emprego não seria sistemático, haja vista que, para certas palavras, como ilustrado em (09), embora sua presença configure, de certa forma, a oposição masculino/feminino, já que a forma de (09a) kizikiaba 'galinha' é privativamente feminina; sua ausência, todavia, não implica exclusividade para o masculino, como observado em (09b), na forma não marcada kiriki 'galo/galinha', cujo significado abrange os dois gêneros. Além disso, para a palavra zin 'mulher, menina', em (11b), nem mesmo qualquer possibilidade de oposição masculino/feminino se estabeleceria, uma vez que esta palavra pertence exclusivamente ao gênero feminino, tendo como contraparte do gênero masculino a forma supletiva daunaiur 'homem', de forma que, na forma żinaba, em (11a), a presença do sufixo - $a b a$ nada acrescenta em termos de significado. Assim sendo, esses fatos conduziram ao tratamento desse sufixo como um termo de classe, ou seja, como instrumento de construção do léxico em vez de um tratamento como morfema flexional, o que lhe atribuiria status gramatical.

Tratar o marcador de feminino de nomes alienáveis - aba como um termo de classe implica necessariamente, como observado na definição deste sistema de classificação 
nominal fornecida acima, que esse morfema tenha origem transparentemente lexical e que opere recorrentemente na formação do léxico, como ocorre no exemplo (01) acima, aqui retomado em (12) para comodidade de exposição:
a. ak-a-i
'fruta'
fruta-EP-NPOSS
b. atamin-ak
'fruta da árvore'
árvore-TCL:fruta
c. wabu-ak
açaí-TCL:fruta
'fruta do açaizeiro'
d. atfawii-ak
alho-do-mato-TCL:fruta
'fruta do alho-do-mato'

Como observado acima, por ocasião da análise do sistema de classificação nominal termos de classe, facilmente se percebe, neste exemplo, a origem nitidamente lexical do termo de classe - ak que provém da palavra $a k a i$ 'fruta' (12a) e opera recorrentemente na formação dos compostos atamin-ak 'fruta da árvore', wabu-ak'fruta do açaizeiro' e atfawii$a k^{\prime}$ fruta do alho-do-mato' (12b-d).

Com relação ao marcador de feminino de nomes alienáveis - $a b a$, todavia, não parece fácil afirmar uma origem lexical. Primeiro, porque não se tem, ao menos no estágio atual do estudo sobre essa língua, como demonstrar sua origem lexical; e, segundo, porque sua aplicação não parece produzir novos compostos, mas antes limitar-se à expressão de gênero quando acionada.

Diante da impossibilidade, em termos de origem, de caracterizar o marcador de feminino - $a b a$ como termo de classe, resta observar a possibilidade de esse morfema constituir um marcador de gênero (ou classes de nomes). Nesse sentido, para que - $a b a$ constitua um marcador de gênero ou classes de nomes, como observado com Dixon (1986) acima, deve obedecer aos seguintes requisitos: (i) integrar um sistema gramatical fechado, quer dizer, sistematicamente aplicar-se a todos os nomes da língua que reúnam os requisitos para sua aplicação; (ii) concorrer a um número restrito de subcategorias; (iii) operar em processos de concordância e (iv) atuar em conjunto com outras categorias gramaticais, tais como a categoria de caso. 
Os requisitos i) e ii) podem ser atestados em exemplos, como os que seguem ${ }^{8}$ :
a. arimaraka- $\varnothing /$ arimarak-aba
'cachorro' / 'cadela'
cachorro-M cachorro-F
b. karaiwa- $\varnothing ~ / ~ k a r a i w a-a b a$
'homem branco' / 'mulher branca'
branco-M branco-F
c. tufau- $\varnothing$ / tufau-aba
'homem líder' / 'mulher líder'
tuxaua-M tuxaua-F

No que diz respeito ao quesito (i), esses exemplos revelam que qualquer nome alienável integrante da subcategoria masculino, cujo referente remeta à entidade dotada de vida e movimento, portanto, que envolva o traço [+animado], condição para a aplicabilidade de $-a b a$, recebe sistematicamente esse morfema para a formação da subcategoria feminino; como se observa em (13a), que envolve a categoria dos animais, em (13b), categoria dos humanos e, em (13c), categoria de autoridades. Com relação ao requisito (ii), verifica-se que as subcategorias possíveis restringem-se a masculino e feminino, portanto, um número bastante limitado como requer o sistema de classificação nominal de gênero (ou classes de nomes). Infere-se, pois, que o paradigma próprio de nomes alienáveis em wapixana constitui um sistema gramatical fechado.

No que tange ao requisito (iii), operar em processos de concordância, também se pode dizer que ele é contemplado, como ilustrado a seguir:
a. tawi- $r$ i: marinau- $\varnothing$
'aquele homem pajé'
DIST-M pajé-M
a'. $\quad$ *tawi- $r \dot{t}:$ marinau- $a b a$
'aquele homem pajé' DIST-M pajé-F
b. tawi- $r u$ : marinau- $a b a$ 'aquela mulher pajé'
DIST-F pajé-F
b'. *tawi- $r$ : marinau- $\varnothing \quad$ 'aquela mulher pajé'
DIST-F pajé-M

Conforme os exemplos em (14), a concordância de gênero em construções que envolvam o paradigma - $\varnothing$ (masculino) oposto a -aba (feminino) é obrigatória, razão pela qual (14a) e (14b), que obedecem ao padrão de concordância de gênero entre o

8 O símbolo $\varnothing$ indica a ausência de marca. 
demonstrativo e o núcleo nominal, respectivamente, para masculino e feminino, são aceitáveis e (14a') e (14b'), por outro lado, não o são, como sinalizado pelo asterisco.

Finalmente, o requisito (iv), atuar em conjunto com outras categorias gramaticais, pode ser demonstrado em exemplos como os que seguem:

$$
\begin{aligned}
& \text { a. pixan- } a b a_{\mathrm{i}} \text { na?ak-a-n pai-dani }{ }_{j} \text { narik } u_{\mathrm{i}} \text {-bidikidi-a-n-i } z_{\mathrm{j}} \\
& \text { gato-F trouxe-EP-MI ANF-filho CONJ 3FS-amementar-EP-MI-3MO } \\
& \text { 'a gata trouxe o filhote e o amamentou' } \\
& \text { b. } \quad{ }^{*} \text { pixan- } a b a_{\mathrm{i}} \text { na?ak-a-n pai-dani }{ }_{\mathrm{j}} \text { naPik } \dot{i}_{\mathrm{i}} \text {-bidikidi-a-n-izz } u_{\mathrm{j}} \\
& \text { gato-F trouxe-EP-MI ANF-filho CONJ 3MS-amementar-EP-MI-3FO } \\
& \text { 'a gata trouxe o filhote e o amamentou' }
\end{aligned}
$$

Em (15), o sufixo -aba na sentença pixanaba na?akan paidani 'a gata trouxe o filho(te)', em (15a), marca como feminino a palavra pixanaba 'gata', enquanto a palavra paidani (literalmente, seu filho) 'seu filho(te)' não apresenta marca de masculino, mas sabese que pertence a esse gênero, porque, se fosse feminino, seria registrada como pai-dani zibaba (literalmente, sua filha mulher). Assim, em acordo com o padrão de concordância da língua, na sentença ubidikidianiz 'ela o amamentou', respectivamente, o prefixo $u$ 'ela' (que remete a pixanaba 'gata' da primeira sentença) e o sufixo - $i z_{z}$ 'o' (que remete a paidani 'seu filho(te)' da primeira sentença) sinalizam, respectivamente, gênero feminino e gênero masculino, razão por que (15b), que traz como prefixo $\dot{i}$ - 'ele' e como sufixo -iz̨u 'a', não é aceita. Importante observar que o prefixo $u$ - 'ela', além de marcar o gênero feminino, marca também o caso nominativo (sujeito) e o sufixo - $i z$, além de marcar gênero masculino, marca concomitantemente caso acusativo (objeto direto), portanto, ambos esses marcadores acumulam as funções de designadores de gênero e de designadores de caso.

Diante do que foi exposto, portanto, o marcador de feminino - aba reúne todos os requisitos de um morfema flexional. Talvez se pudesse opor a isso o fato de esse marcador de gênero feminino e o marcador de concordância não se identificarem formalmente, por exemplo, em tawitu: marinauaba 'aquela (mulher) pajé', em que o sufixo de feminino -ru: no demonstrativo tawiru: 'aquela' não apresenta similaridade com o marcador de feminino -aba do núcleo nominal matinauaba com o qual estabelece a concordância. 
- | O marcador de gênero feminino -aba do Wapixana (Aruák)

Todavia, tal fato não deve constituir um obstáculo, como se observa na posição assumida por Fedden e Corbett (2017, p. 7, tradução nossa9 $)$, que segue:

Adotamos uma abordagem inferencial-realizacional da morfologia, que torna o morfema supérfluo. Uma palavra flexionada [...] possui uma especificação morfossintática associada a ela [...] e isso licencia as regras apropriadas para determinar sua forma.

Portanto, desse ponto de vista, a identidade formal é pouco relevante, o que interessa é a especificação morfossintática, nesse caso, o gênero feminino, que licencia a regra de determinação da forma. Assim, diferenças nas formas de representação desse conteúdo (-ru ou -aba) não retiram o status flexional de -aba.

As construções do exemplo (09), apresentado acima e aqui retomada em (16) para fins de exposição, entretanto, parecem sugerir a impossibilidade de se considerar o sufixo -aba como flexional:
a. kitiki-aba
'galinha'
galo/galinha-TCL:F
b. kitiki
'galo/galinha'
galo/galinha

Assim, se tanto kitriki-aba (galo-feminino) 'galinha', a forma com o sufixo -aba, em (16a), quanto kiriki 'galo/galinha', forma desprovida desse sufixo, em (16b), podem ser interpretados como caracterizando o gênero feminino, a ausência do sufixo - $a b a$ não estaria implicando exclusividade para o masculino, logo o emprego desse sufixo não seria sistemático como requer o status flexional. Ocorre que, se isso é fato, também é fato que a expressão marcada, isto é, kititkiaba 'galinha' nunca é empregada com referência apenas a 'galo' (*kirikiaba 'galo'), o que sinaliza ser kiriki 'galo/galinha' a forma correspondente à categoria semântica básica, razão por que é não marcada ou marcada pela ausência de morfe, isto é, por zero, como se pode observar a partir do fragmento:

9 No original: "We take an inferential-realizational approach to morphology, which makes the morpheme superfluous. An inflected word [...] has a morphosyntatic especification associated with it [...] and this licenses the appropriate rules to determine its form.". 
Jakobson observou em 1939 que havia um significado para a ocorrência de zeros. Eles tendem a ocorrer nos membros não marcados das categorias. O principal critério de Jakobson para o membro não marcado de uma oposição é semântico: enquanto o membro marcado de uma categoria sinaliza a presença de uma propriedade, o membro não marcado é ambíguo: pode ser usado para indicar a ausência dessa propriedade ou pode ser usado de maneira neutra em que nada seja indicado sobre essa propriedade. (BYBEE, 1985, p. 52, tradução nossa $\left.{ }^{10}\right)$.

Assim, o fato de uma palavra não marcada pelo sufixo - aba do wapixana, como kir $r$ kit 'galo/galinha', remeter tanto a entidades dotadas do sexo masculino quanto a entidades do sexo feminino não implica que o acionamento desse morfema seja assistemático, como supôs Santos (2006), e sim que, sendo a forma do masculino (kíriki 'galo/galinha') de sentido mais geral, logo, a forma não marcada do paradigma, pode ser usada em um sentido neutro, sem fazer referência à propriedade de gênero, conforme o propósito comunicativo do falante.

De igual forma, também o fato de tanto a forma despida de -aba, zin, quanto a forma marcada por esse sufixo zinaba poderem ser usadas indiferentemente para designar "mulher" na língua wapixana, não parece constituir obstáculo para se considerar esse sufixo como flexional. Primeiro, porque, como reconhecido por Santos (loc. cit.), esse caso não envolve oposição paradigmática, haja vista que a palavra zin é inerentemente especificada como gênero feminino, sendo o referente masculino expresso lexicamente pela palavra inerentemente masculina daunaiura 'homem'; logo, esse emprego específico de -aba sugere apenas uma redundância, recurso utilizado por falantes para reforçar informações conforme seus propósitos comunicativos. Segundo, porque o vínculo de sentido entre a palavra zin "mulher" e a noção de feminino nessa língua parece ser tão estreito que um nome como danii 'filho' que, segundo o padrão de expressão de gênero da língua, enquanto termo de parentesco, deveria receber o sufixo - ru para marcar o feminino, desviando-se da regra, porém, tem sua expressão de feminino pela formação do composto dani zinaba 'filha', sugerindo mesmo que a forma zinaba 'mulher' encerra o próprio significado de feminino. Vale notar ainda que, ao menos até o presente, não se tem notícia de outra palavra que possa apresentar ou não alternativamente o sufixo - $a b a$ na expressão de gênero feminino.

10 No original: "Jakobson observed in 1939 that there was a significance to the occurrence of zeroes. They tend to occur in the unmarked members of categories. Jakobson's main criterion for the unmarked member of an opposition is a semantic one: while the marked member of a category signals the presence of a property, the unmarked member is ambiguous - it may be used to indicate the absence of that property, or it may be used in a neutral way in which nothing at all is indicated about that property.". 


\section{Considerações finais}

Neste artigo, realizamos uma releitura acerca do status do marcador de gênero - aba da língua wapixana, apresentando evidências de que tal morfema não constitui um termo de classe, como registrado por Santos (2006), mas deve ser tratado como uma típica desinência de gênero.

As razões para essa posição por nós assumida respaldam-se no fato de que esse morfema atende a quatro requisitos exigidos para que um item tenha status de unidade flexional, a saber: (i) integrar um sistema gramatical fechado, quer dizer, sistematicamente aplicar-se a todos os nomes da língua que reúnam os requisitos para sua aplicação; (ii) concorrer a um número restrito de subcategorias; (iii) operar em processos de concordância e (iv) atuar em conjunto com outras categorias gramaticais, tais como a categoria de caso (DIXON, 1986). Em consequência, tal marcador integra um paradigma regular, sendo acionado sistematicamente para a expressão de gênero das construções que o requerem, o que implica que não compõe o sistema de gênese do léxico, como deveria, se fosse um termo de classe.

Acerca do emprego facultativo desse marcador de gênero, fato que impediria de tratá-lo como um elemento gramatical (flexional), observou-se que se trata tão somente de empregos específicos decorrentes dos propósitos comunicativos do falante, seja em função de uso da forma básica do masculino, a expressão não marcada por - $a b a$, de forma neutra, isto é, sem fazer referência à propriedade especificada de gênero, seja como recurso redundante de ênfase.

Os estudos sobre os fenômenos linguísticos que ocorrem na língua wapixana ainda são incipientes e temas relacionados ao gênero, certamente, ainda vão suscitar muitos trabalhos, mas acreditamos que esse artigo vem contribuir para lançar mais clareza sobre o tema apresentado.

\section{Referências}

AIKHENVALD, A. Y. (org.). The Amazonian Languages. Cambridge: Cambridge University Press, 1999. p. 65-106.

BYBEE, J. Morphology a study of the relation between meaning and form. Amsterdam/ Philadelphia: John Benjamins Publishing Company, 1985. 
DELANCEY, S. Toward a history of Tai classifier systems. In: CRAI, C. Noun classes and categorization. Amsterdam/Philadelphia: John Benjamins, 1986. p. 437-452.

DIXON, R. M. W. Noun classes and noun classification in typological perspective. In:

CRAI, C. Noun classes and categorization. Amsterdam/Philadelphia: John Benjamins, 1986. p. 105-112.

ENFIELD, N. J. Ethnosyntax: explorations in grammar and culture. New York: Oxford University Press, 2004.

FARAGE, N. As flores da fala: práticas retóricas entre os Wapishana. 1997. Tese (Doutorado em Letras) - Faculdade de Filosofia, Letras e Ciências Humanas, Universidade de São Paulo, São Paulo, 1997.

FEDDEN, S.; CORBETT, G. Gender and classifiers in concurrent systems: refining the typology of nominal classification. Glossa: a journal of general linguistics, v. 2, n. 1 (34), p. 1-47, 2017. DOI: https//doi.org/10.5334/gjgl.177

GRINEVALD, C. A morphosyntactic typology of classifiers. In: SENFT, G. Systems of nominal classification. Cambridge: Cambridge University Press. 2000. p. 50-92.

LAKOFF, G. Women, fire, and dangerous things: what categories reveal about the mind. Chicago: University of Chicago, 1987.

MELO, I. P. de. Um estudo sobre a concordância de gênero em Wapixana (Aruák). 2019. Dissertação (Mestrado em Letras) - Universidade Federal de Roraima, Boa Vista, 2019.

PAYNE, D. L. A classification of Maipuran (Arawakan) languages based on shared lexical retentions. In: DERBYSHIRE, D. C.; PULLUM, G. K. (org.). Handbook of Amazonian languages. Berlin/New York. Mouton: De Gruyter. 1991. v. 3. p. 355-499.

RODRIGUES, A. D. Línguas brasileiras - para o conhecimento das línguas indígenas. São Paulo: Loyola. 1986.

RODRIGUES, A. D. Línguas Indígenas Brasileiras. Brasilia: UNB-LALI, 2013. 
- | O marcador de gênero feminino -aba do Wapixana (Aruák)

SANTOS, M. G. Uma gramática do Wapixana (Aruák) - aspectos da fonologia, da morfologia e da sintaxe. 2006. Tese (Doutorado em Linguística) - Instituto de Estudos da Linguagem, Universidade Estadual de Campinas, Campinas, 2006.

SAPIR, E. Linguística como ciência. Tradução Mattoso Câmara Jr. Rio de Janeiro: Acadêmica, 1969.

COMO CITAR ESTE ARTIGO: SANTOS, Manoel Gomes dos; ANJOS, Zoraide dos. O marcador de gênero feminino -aba do Wapixana (Aruák). Revista do GEL, v. 17, n. 2, p. 196-213, 2020. Disponível em: https://revistadogel.gel.org.br/

DOI: http://dx.doi.org/10.21165/gel.v17i2.2749

Submetido em: 12/10/2019 | Aceito em: 25/06/2020. 